\title{
OPTIMIZATION OF FORMULATION OF SOLID DISPERSION OF FUROSEMIDE BY FACTORIAL DESIGN
}

\author{
SHARWAREE R. HARDIKAR*, SHAKIL S. MULLA \\ Department of Pharmaceutics, MCE Society's Allana College of Pharmacy, Pune 411001, India \\ Email: sharwareehardikar@gmail.com
}

Received: 20 Nov 2019, Revised and Accepted: 25 Feb 2020

\begin{abstract}
Objective: The present study aimed to improve the rate of dissolution of furosemide by solid dispersion technique.

Methods: Solid dispersion of furosemide was prepared by using hydrogel isolated from the seeds of Lepidium sativum as a novel carrier by the solvent evaporation method. Solid dispersion was evaluated to study the improvement in the rate of dissolution. Molecular dispersion of furosemide in the novel carrier was studied by DSC and FTIR studies. Solid dispersion was filled in capsules after stability studies and the formulation was optimized by adopting factorial design.
\end{abstract}

Results: Solid dispersion of furosemide exhibited dissolution improvement from $13.54 \%$ (plain furosemide) to $69.12 \%$ (solid dispersion) in the first $60 \mathrm{~min}$. Improvement in dissolution efficiency was found to be retained after stability studies. Capsules were filled with the formulation of solid dispersion using two different grades of lactose- $\alpha$ lactose monohydrate and anhydrous lactose and were found stable after stabilization studies.

Conclusion: The dissolution improvement of furosemide was attributed to its molecular dispersion in the novel carrier selected for this study. The recrystallization of furosemide was prevented due to intermolecular interaction between the novel carrier and furosemide. This was confirmed by FTIR. Evaluation of the dissolution data of factorial batches was analyzed by ANOVA. Analysis of the data revealed that selected levels of $\alpha$ lactose monohydrate and anhydrous lactose would be useful to navigate design space.

Keywords: Furosemide, Dissolution, Hydrogen bonding, Solid dispersion

(C) 2020 The Authors. Published by Innovare Academic Sciences Pvt Ltd. This is an open access article under the CC BY license (http://creativecommons.org/licenses/by/4.0/) DOI: http://dx.doi.org/10.22159/ijpps.2020v12i4.36428. Journal homepage: https://innovareacademics.in/journals/index.php/ijpps

\section{INTRODUCTION}

Furosemide is a BCS class IV drug and is a weakly acidic loop diuretic used for oral treatment of edema and hypertension. It shows the variable rate and extent of absorption resulting in poor oral bioavailability $(37 \%-51 \%)$. It is a substrate for the P-gp efflux system expressed in lower GIT and hence it is poorly permeable. Since poor permeability of furosemide is due to its efflux in the lower small intestine; enabling dissolution of furosemide to the extent to ensure its adequate absorption through upper GIT is sufficient to improve its bioavailability $[1,2]$. Solid dispersion is a widely adopted formulation approach to enable dissolution because of its feasibility, reproducibility, and ease of optimization. Molecular dispersion of furosemide in a selected novel carrier was prepared in the present study. It is reported that if water-soluble carriers ate preferred; the incidence of recrystallization of a molecularly dispersed drug is reduced. Therefore molecular dispersion of furosemide was prepared with hydrogel isolated from the seeds of Lepidium sativum as a novel hydrophilic carrier $[3,4]$. In an attempt to improve the dissolution of a drug through its molecular dispersion in a hydrophilic carrier; the recrystallization of a drug during storage is a point of major concern. This problem can be mitigated by proper polymer selection. Suitable material that is capable of interacting with drug molecules through hydrogen bonding is expected to prevent the recrystallization. The hydrogel was isolated from the seeds of Lepidium sativum (gel) and used in this study as novel material as it was studied as a disintegrating agent and reported by Patel et al.; 2011 [5-8].

The stability of molecular dispersion of furosemide was confirmed and its formulation to be filled in capsules was developed and optimized by adopting factorial design. Lactose is routinely used diluent/filler in capsule dosage forms. Crystalline $\alpha$-lactose monohydrate and crystalline anhydrous lactose are the most frequently used forms of lactose in the pharmaceutical industry. The present work aimed to improve the dissolution of furosemide. Hence, the influence of lactose as one of the major components of the formulation; on the dissolution efficiency of molecularly dispersed furosemide was necessary to be assessed. The grade of lactose was selected as one variable factor and amount of silicon dioxide as the second variable factor. Silicon dioxide is a hydrophobic lubricant; the study of its effect on the dissolution of furosemide was required $[9,10]$. Design Expert (Demo version 11Stat-Ease, Inc, USA) was used for the analysis of the effect of each variable on the designated response i.e. dissolution efficiency. The analysis of data suggested that the selected levels of factors (two grades of lactose and the amount of silicon dioxide) can be used to navigate the design space [11].

\section{MATERIALS AND METHODS}

\section{Materials}

Furosemide was obtained as a gift sample from Cipla Ltd. Kurkhumbh, India. Seeds of Lepidium sativum were purchased from a local source and were authenticated CSIR-National Botanical Institute (authentication number-LWG-46) and deposited in National Repository, Lucknow, India. All other chemicals used in the analysis were of analytical grade and others were at least of pharmaceutical grade and used without further purification.

\section{Methods}

Isolation of hydrogel from the seeds of Lepidium sativum

The hydrogel was isolated from whole seeds of Lepidium Sativum by soaking them in demineralized water. The entire bulk was homogenized and passed through a muslin cloth to obtain the gel.

\section{FTIR of hydrogel obtained from the seeds of Lepidium sativum}

The gel was isolated from the seeds of Lepidium Sativum, and dried in hot air oven (at $80{ }^{\circ} \mathrm{C}$ for sufficient time to remove the water completely) and taken for FTIR analysis. Powder of potassium bromide $(\mathrm{KBr})$ was heated for $1.5 \mathrm{~h}$. to remove moisture at $160{ }^{\circ} \mathrm{C}$. Dried Gel was mixed thoroughly with $\mathrm{KBr}$ in the proportion of 1:1. 
The FTIR spectrum was recorded using a JASCO FTIR instrument. The result was obtained in the form of a graph of \% Transmittance vs. Wave no. Then the mixture was scanned over the $400-4000 \mathrm{~cm}^{-1}$.

\section{Preparation of solid dispersion of furosemide}

Gel (mucilage) isolated from the seeds of Lepidium sativum was used in the preparation of solid dispersion of Furosemide. Solid dispersion of Furosemide was prepared by adopting the solvent evaporation method [12]. Furosemide was dissolved in ethanol (50 ml). Sufficient amount of gel was mixed with an ethanolic solution of furosemide in to attain 1:1, 1:2 and 1:3 proportions by weight of furosemide and dried Gel. The mixture was homogenized for $30 \mathrm{~min}$ and then was dried in an oven for $50 \mathrm{~min}$ at $80{ }^{\circ} \mathrm{C}$. These solid dispersions were characterized and evaluated for dissolution studies.

\section{Characterization and evaluation of solid dispersion of} furosemide

\section{Uniformity of content of furosemide in solid dispersion}

The sufficient amount of solid dispersion equivalent to $40 \mathrm{mg}$ of furosemide was weighed accurately. The actual amount of furosemide present in solid dispersion was determined by dissolving it in $50 \mathrm{ml}$ of dimethyl-formamide to which has been added 3 drops of Bromothymol blue T. S. which previously has been neutralized $0.1 \mathrm{~N} \mathrm{NaOH}$; titrated with $0.1 \mathrm{~N} \mathrm{NaOH}$ [13].

\section{FTIR analysis of solid dispersion}

FTIR of solid dispersion recorded to study molecular interaction between furosemide and gel. Potassium bromide $(\mathrm{KBr})$ was heated for $1.5 \mathrm{hr}$. at $160^{\circ} \mathrm{C}$ to remove moisture. Solid dispersion was mixed thoroughly with $\mathrm{KBr}$ in the proportion of 1:1. The FTIR spectrum of the solid dispersion was recorded using a JASCO FTIR instrument. The result was obtained in the form of a graph of $\%$ Transmittance vs. Wave no. Then the mixture was scanned over the $400-4000 \mathrm{~cm}^{-1}$.

\section{Determination of dissolution efficiency of solid dispersion of furosemide}

Solid dispersion equivalent to the $40 \mathrm{mg}$ of furosemide was weighed accurately and put in the vessel of the USP II dissolution apparatus containing $900 \mathrm{ml}$ of phosphate buffer $\mathrm{pH}$ 5.8. The dissolution medium was maintained at $37{ }^{\circ} \mathrm{C} \pm 0.5^{\circ} \mathrm{C}$. The speed of the rotating shaft was $50 \mathrm{rpm}$. The aliquots of $5 \mathrm{ml}$ were withdrawn at predetermined time intervals, filtered and diluted sufficiently. The absorption was measured at $277 \mathrm{~nm}$ and the cumulative amount dissolved was calculated. The dissolution efficiency (D. E.) of solid dispersion is the area under the dissolution curve of the rectangle described by $100 \%$ dissolution in the same time [14]. It was calculated by the following equation-

$$
\text { D. E. }=\frac{0 \int \mathrm{ty} \times \mathrm{dt}}{\mathrm{y} 100 \times \mathrm{t}} \times 100-\cdots
$$

Where ' $y$ ' is the drug percent dissolved at the time ' $t$ '.

\section{Stability study}

Stability studies were conducted for the solid dispersion of Drug: Gel in 1:3 proportions to confirm the dissolution improvement even after the stability period. Solid dispersion was packed in aluminum foil and exposed to $40^{\circ} \mathrm{C} / 75 \% \mathrm{RH}$ for two months according to the guidelines from the International Council for Harmonization (ICH) [15]. Solid dispersion was evaluated for the parameters as uniformity of content, dissolution efficiency and DSC.

\section{Optimization of the capsule as a dosage form by factorial design}

Bulk formulations of solid dispersion were prepared by mixing the appropriate quantity of solid dispersion with $62.5 \%$ lactose ( $\alpha$ monohydrate and anhydrous) as a filler/diluent and silicon dioxide $1.5 \%$ as a glidant for $10 \mathrm{~min}$. A $2^{2}$ full factorial design was used for the optimization of the composition of the bulk of solid dispersion to be filled in capsules $[16,17]$. According to the model it contained 2 independent variables at 2 levels, $+1,-1$. According to the model, the total four formulations are possible, the composition of the different formulation is shown in table 1 . The different independent variables were $\alpha$ lactose monohydrate or anhydrous lactose (X1) and the amount of colloidal silicon dioxide (X2). The factor levels were chosen to their relative alteration was acceptable to have powder bulk with flow property (i.e. if the angle of repose was between 28 to 34 ) and compressibility (i.e. Hausner's ratio between 1.12 to 1.2). The dependent factor included dissolution efficiency at $60 \mathrm{~min}$ after stability studies. Stability studies of all the factorial formulations were conducted. All formulations were exposed to $40^{\circ} \mathrm{C} / 75 \% \mathrm{RH}$ for three months according to the guidelines from the International Council for Harmonization (ICH) and were evaluated for dissolution studies. Design Expert (Demo version 11-Stat-Ease, Inc, USA) was used for the analysis of the effect of each variable on the designated response i.e. dissolution efficiency. The significant response polynomial equations generated by Design Expert were used to validate the statistical design. Response surface plots were generated to visualize the simultaneous effect of each variable on each response parameter. The constant and regression coefficients were also calculated using the software.

Table 1: Composition of powder blend for preparation of factorial batches

\begin{tabular}{|c|c|c|c|c|}
\hline $\begin{array}{l}\text { Ingredients (mg/capsule) } \\
\text { formulation code }\end{array}$ & $\begin{array}{l}\text { FRU SD equivalent } \\
\text { to } 40 \mathrm{mg} \text { of CLA }\end{array}$ & Lactose* & Colloidal silicon dioxide & Total weight of the tablet \\
\hline F1 (-,-) & 160 & 100 & 4 & 264 \\
\hline $\mathrm{F} 2(+,-)$ & 160 & 100 & 4 & 264 \\
\hline F3 $(-,+)$ & 160 & 100 & 8 & 268 \\
\hline $\mathrm{F} 4(+,+)$ & 160 & 100 & 8 & 268 \\
\hline
\end{tabular}

* F1 and F3 were prepared by using $\alpha$ lactose monohydrate and F2 and F4 were prepared by using anhydrous lactose.

Table 2: Translation of coded value in actual unit

\begin{tabular}{lll}
\hline Variable level & - & + \\
\hline $\mathrm{X} 1=$ Grade of lactose & $\alpha$ lactose monohydrate & Anhydrous lactose \\
$\mathrm{X} 2=$ Colloidal silicon oxide & $04 \mathrm{mg}$ & $08 \mathrm{mg}$ \\
\hline
\end{tabular}

\section{RESULTS AND DISCUSSION}

\section{Isolation of hydrogel from the seeds of lepidium sativum}

The hydrogel was isolated from whole seeds of Lepidium Sativum and the appearance of the gel was translucent and brownish. The specific gravity of the gel was found to be 1.009 and was comparable to water revealing very high water uptake by the gel-forming material.

\section{FTIR of hydrogel obtained from the seeds of Lepidium sativum}

The composition of Gel is reported in the literature. It contains arabinose, xylose and rhamnose and the highest amount of uronic acid (galacturonic acid+glucuronic acid). FTIR spectrum of the dried is shown in fig. 1. The spectra exhibited all typical bands and peaks characteristic of polysaccharides. The major identical peaks are similar and in good agreement with those reported for Lepidium 
sativum seed mucilage. A band around $2921 \mathrm{~cm}^{-1}\left(3000-2800 \mathrm{~cm}^{-1}\right)$ referred to $\mathrm{C}-\mathrm{H}$ vibrations, which included $\mathrm{CH}, \mathrm{CH} 2$ and $\mathrm{CH} 3$ stretching and bending vibrations, symmetric, and asymmetric and occasionally doubles overlapping with $\mathrm{O}-\mathrm{H}$. The characteristic bands around $1668 \mathrm{~cm}^{-1}$ and $1463 \mathrm{~cm}^{-1}$ were attributed to the asymmetrical and the symmetrical COO-stretching vibrations, respectively. The peak at $1066 \mathrm{~cm}^{-1}$ indicated the presence of carbohydrates $[18,19]$.

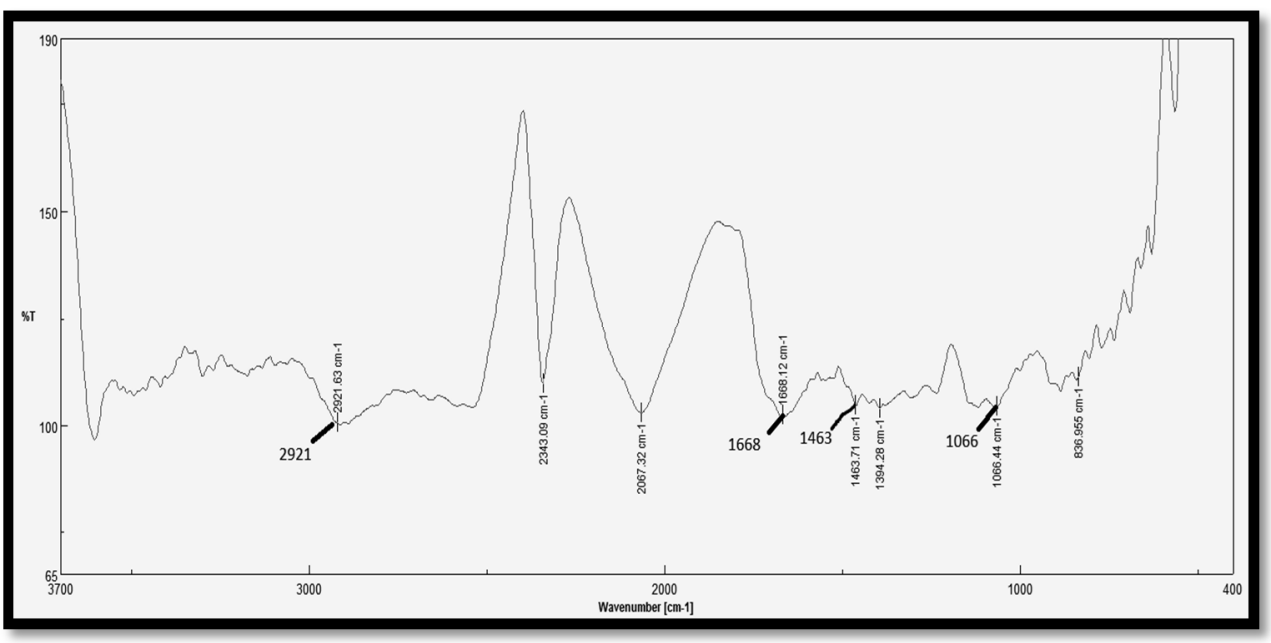

Fig. 1: FTIR spectrum of dried mucilage of Lepidium sativum

\section{Preparation of solid dispersion of furosemide}

\section{Uniformity of content of furosemide in solid dispersion}

Solid dispersion was prepared in three lots and was faint brown in appearance. The yield was calculated and it was found to be more than $95 \%$. The uniformity of the content of furosemide in its solid dispersion form was found to be $96.12 \% \pm 1.74$. Further calculations were done with necessary corrections accordingly.

\section{FTIR analysis of solid dispersion}

FTIR spectra of plain furosemide (fig. 2) and its solid dispersion (fig. 3 ) were compared and revealed hydrogen bonding between them. The characteristic peak of the primary amine $\left(\mathrm{NH}_{2}\right)$ group that was observed at $1568 \mathrm{~cm}^{-1}$ in FTIR of plain furosemide was downshifted at1430 $\mathrm{cm}^{-1}$ in FTIR of solid dispersion of furosemide. Similarly, the characteristic peak of the ketone carbonyl group that was observed at $1678 \mathrm{~cm}^{-1}$ in FTIR of plain furosemide was downshifted at 1611 $\mathrm{cm}^{-1}$ in FTIR of solid dispersion of furosemide. The broadening of the absorption band in the $\mathrm{OH}$ stretching region also indicated intermolecular hydrogen bonding $[20,21]$.

\section{Determination of dissolution efficiency of solid dispersion of furosemide}

In an attempt to design a scalable manufacturing method of solid dispersion, the amount of carrier needed to achieve the desired improvement in dissolution characteristics of the drug is a major factor. The gel was selected as a novel carrier in the present study. Hence, the solid dispersion of Drug: Gel was prepared by using gel in increasing proportions and its influence on dissolution characteristics of the furosemide was carefully studied. As the proportion of gel was increased in the preparation of solid dispersion, dissolution was found to be gradually increased. There was an increase in the dissolution efficiency of furosemide in its solid dispersion form (in proportion 1:3) when compared to that with plain furosemide as from $13.54 \%$ to $69.12 \%$ in first 60 min (table 3 and fig. 4). This improvement was statistically significant [22]. This might be due to the well-reported wetting effect of the hydrophilic gel that is used as a novel carrier in the present study and molecular dispersion of the furosemide in the carrier system [23].

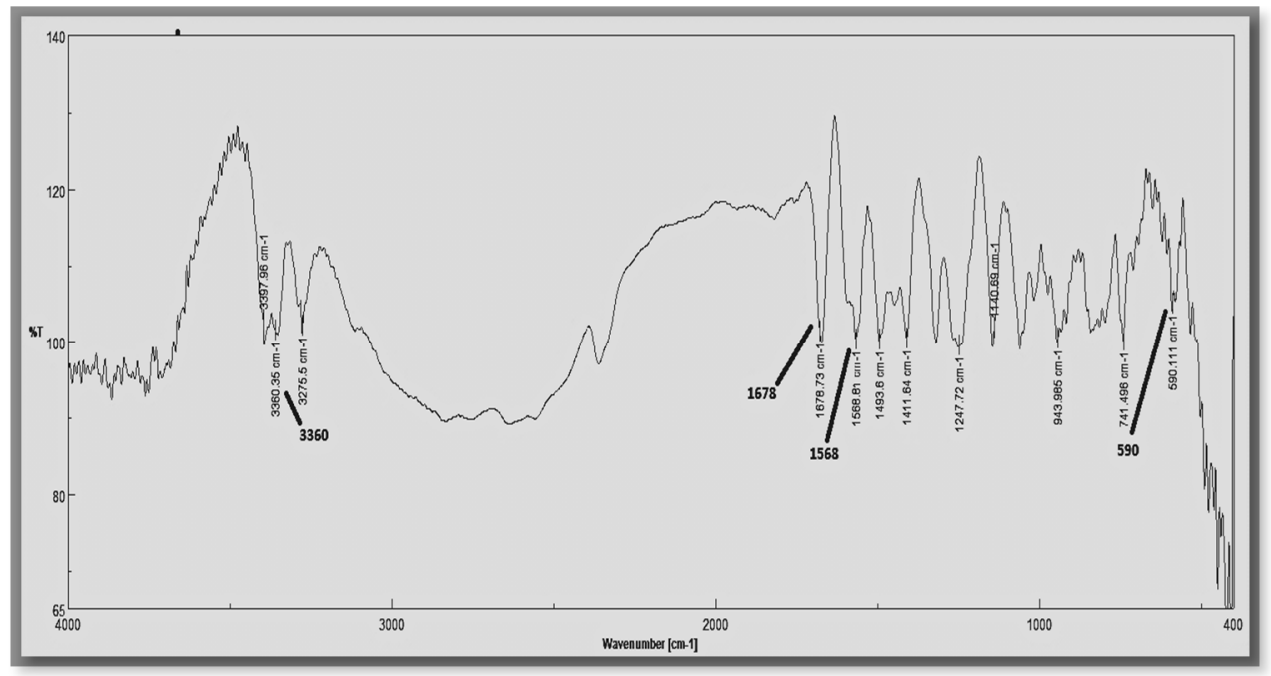

Fig. 2: FTIR spectrum of furosemide 


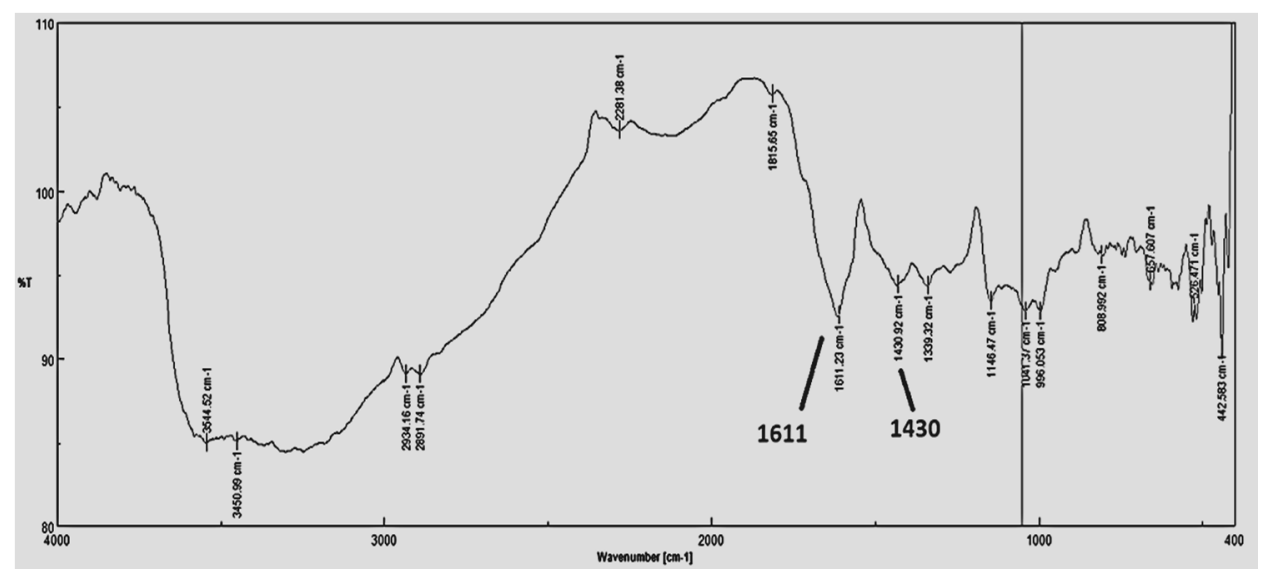

Fig. 3: FTIR spectrum of solid dispersion of furosemide

Table 3: Percent cumulative dissolution data for SD of furosemide and plain furosemide

\begin{tabular}{|c|c|c|c|c|}
\hline \multirow{2}{*}{$\begin{array}{l}\text { Time } \\
\text { (min) }\end{array}$} & \multirow[t]{2}{*}{ Plain furosemide } & \multicolumn{3}{|c|}{ \% Cumulative dissolution for solid dispersions of various proportions of the drug: gel* } \\
\hline & & $1: 1$ & $1: 2$ & $1: 3$ \\
\hline 00 & 00 & 00 & 00 & 00 \\
\hline 05 & $5.88 \pm 0.19$ & $29.55 \pm 0.29$ & $25.85 \pm 0.12$ & $40.17 \pm 0.11$ \\
\hline 10 & $8.61 \pm 0.31$ & $32 \pm 0.23$ & $36.83 \pm 0.21$ & $54.77 \pm 0.23$ \\
\hline 15 & $11.01 \pm 0.11$ & $33.38 \pm 0.12$ & $49.9 \pm 0.25$ & $60.83 \pm 0.06$ \\
\hline 20 & $13.5 \pm 0.23$ & $38.94 \pm 0.12$ & $62.14 \pm 0.13$ & $63.40 \pm 0.20$ \\
\hline 25 & $14.86 \pm 0.49$ & $39.77 \pm 0.15$ & $66.47 \pm 0.32$ & $68.22 \pm 0.10$ \\
\hline 30 & $15.16 \pm 0.17$ & $40.33 \pm 0.22$ & $66.13 \pm 0.08$ & $74.35 \pm 0.30$ \\
\hline 45 & $16.19 \pm 0.33$ & $40.55 \pm 0.20$ & $71.19 \pm 0.12$ & $84.38 \pm 0.21$ \\
\hline 60 & $18.55 \pm 1.6$ & $43.33 \pm 0.18$ & $75.65 \pm 0.23$ & $93.55 \pm 0.21$ \\
\hline
\end{tabular}

*All values indicate mean \pm SD $(n=3)$

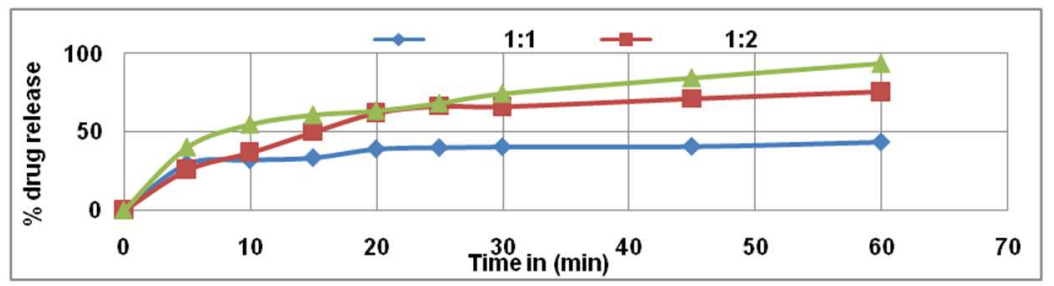

Fig. 4: Percent cumulative drug release of different furosemide: gel ratio's

\section{Stability study}

In the overall developments in amorphous solid dispersions, recrystallization of the drug in solid dispersion form i.e. physical stability of the dispersion is a factor of serious concern. The strategy to stabilize the molecular dispersion/amorphous form of a drug in its solid dispersion demands interactions such as hydrogen bonding between the drug and hydrophilic polymer used in the solid dispersion [24]. FTIR study already revealed hydrogen bonding between furosemide and gel. Therefore stability studies were planned and conducted to confirm the stability of molecular dispersion/amorphous form of a drug in its solid dispersion. Uniformity of content of furosemide remained above $95 \%$ even when the solid dispersion was exposed to $40^{\circ} \mathrm{C} / 75 \% \mathrm{RH}$ i.e. after stability testing studies for two months. Dissolution efficiency was found to be $68.33 \%$. Differential Scanning calorimetry was performed to confirm the amorphous nature of the drug in solid dispersion. The DSC scans of furosemide in its solid dispersion recorded at the end of stability studies revealed that the drug exothermic characteristic peak (fig. 5) disappeared completely. This might be explained based on the homogeneous dispersion of furosemide in hydrophilic carrier i.e. gel [25]. Therefore it was concluded that the marked improvement in the dissolution of furosemide was due to molecular dispersion/amorphization of the furosemide in the hydrophilic gel. The recrystallization of furosemide was mitigated due to intermolecular hydrogen bonding between the furosemide and novel carrier selected in the present study. Solid dispersion of Furosemide: gel in 1:3 proportions was taken further to develop its suitable dosage form.

\section{Optimization of the capsule as a dosage form by factorial design}

Recrystallization of the amorphous form of a drug is promoted due to the application of the compression force [26]. Also, most of the formulations are filled into the capsules for the conduct of clinical trials. Therefore capsules as drug delivery systems were selected in the present study. The formulation to be filled in the capsules requires a specific flow and density profile. Lactose is a wellaccepted excipient, widely used as a diluent, filler-bulking agent in the capsule as a solid oral dosage form. It is available in various grades with different physical properties. Various grades of lactose are available and are routinely used in the bulk formulations to be filled in the capsules. The process demands a specific grade of lactose to make the bulk free-flowing to somewhat cohesive for a specific formulation. Two different grades of lactose- $\alpha$ lactose monohydrate or crystalline anhydrous lactose were selected as diluents to prepare the bulk of solid dispersion to be filled in capsules [27]. The levels of lactose were selected based on the evaluation of preliminary bulk formulations and the recommended amounts for BCS class IV compounds [28]. Preliminary bulk 
formulations were prepared by mixing lactose of either grade in the proportion reported to be appropriate for BCS class IV API (furosemide). The bulk formulations that exhibited acceptable flow properties, as well as compressibility, were further selected for optimization of the formulation by adopting factorial design. Silicon dioxide was used as a glidant. Capsules were evaluated for contents of the active ingredient and were found $98.85 \% \mathrm{w} / \mathrm{w}$. Three capsules from each factorial batch were taken for measurement of dissolution efficiency and the results are reported in table 4.

The data obtained after evaluation of factorial batches were analyzed by using the demo version of commercially available software Design Expert (Version 11). To describe the response surface curvature (fig. 5), the design was evaluated by the quadratic model, which bears the form of the equation-

D. E. $(\mathrm{Y})=68.34+0.45 \mathrm{X} 1-0.02 \mathrm{X} 2-0.01 \mathrm{X} 1 \mathrm{X} 2$

Anhydrous lactose exhibited faster dissolution than when lactose monohydrate was used; as indicated by the positive coefficient of $\mathrm{X}_{1}$. As the amount of silicon dioxide was increased in the formulation the dissolution rate slowed down; as indicated by the negative coefficient of $X_{2}$. The high numerical value of the coefficient of $X_{1}$ indicated that the grade of lactose used in the formulation has more impact on dissolution than the amount of silicon dioxide added. The interaction between factor $X_{1}$ and $X_{2}$ was not considerable and both were found to negate the effect of each other to some extent. It was obvious by the negative coefficient of $\mathrm{X}_{1} \mathrm{X}_{2}$.

Analysis of the evaluation data generated for dissolution efficiency by applying ANOVA suggested that the significant factors affecting dissolution efficiency were the grade of lactose and the amount of silicon dioxide. $\mathrm{F}$ value for silicon dioxide and the interaction term was at $p \geq 0.05$ and suggested low confidence in the inference drawn. Thus, the effect of silicon dioxide on the dissolution efficiency of solid dispersion has to be planned with logical modifications to refine the results. Design space is applicable to scale up and to a site change and working within a design space is not considered as a change. As per ICH Q8 (R2) guidelines, the factorial design was adopted to establish design space. The fit statistics (table 5) suggested that the selected levels of factors (two grades of lactose and the amount of silicon dioxide) can be used to navigate the design space.

Table 4: Dissolution efficiency (\%) for factorial batches

\begin{tabular}{lllll}
\hline Formulation & F1 $(-,-)$ & F2(+,-) & F3(-,+) & F4(+,+) \\
\hline D. E. $(\%)$ & $67.90 \pm 0.32$ & $68.82 \pm 0.26$ & $68.16 \pm 0.26$
\end{tabular}

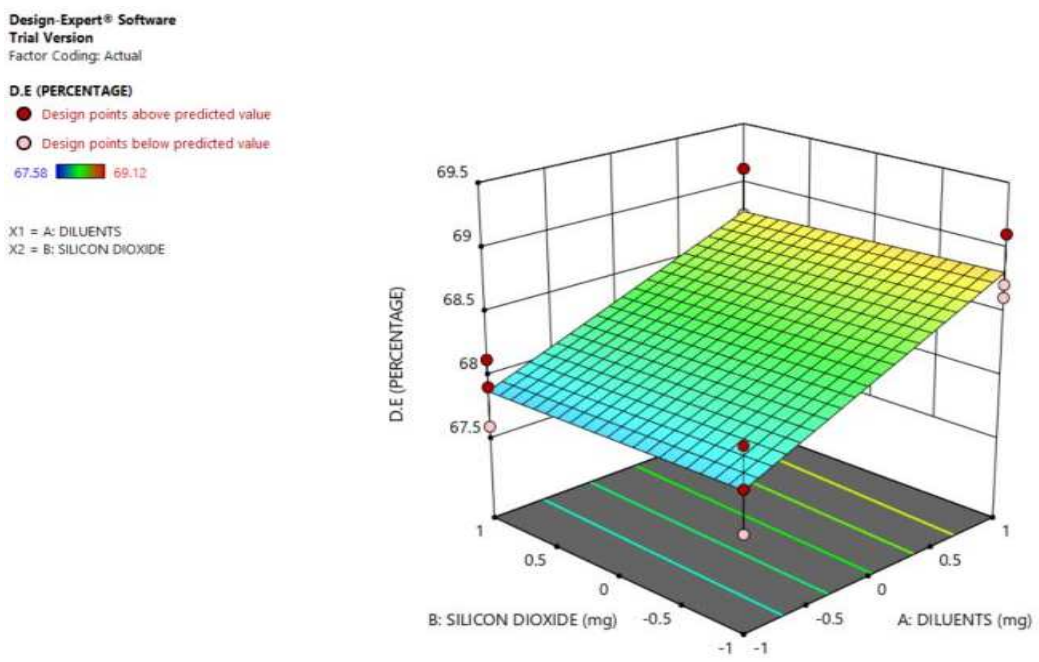

Fig. 5: Surface response curvatures

Table 5: Analysis of data after applying anova

ANOVA for selected factorial model

Response 1: D.E

\begin{tabular}{|l|r|r|r|r|r|}
\hline \multicolumn{1}{|c|}{ Source } & $\begin{array}{c}\text { Sum of } \\
\text { Squares }\end{array}$ & of & $\begin{array}{c}\text { Mean } \\
\text { Square }\end{array}$ & F-value & p-value \\
\hline Model & 2.41 & 3 & 0.8034 & 8.69 & 0.0067 significant \\
\hline A-DItUENTS & 2.40 & 1 & 240 & 26.00 & 0.0009 \\
\hline B-SILCON DIOXIDE & 0.0061 & 1 & 0.0061 & 0.0657 & 0.8041 \\
\hline AB & 0.0010 & 1 & 0.0010 & 0.0109 & 0.9194 \\
\hline Pure Error & 0.7393 & 8 & 0.0924 & & \\
\hline Cor Total & 3.15 & 11 & & & \\
\hline
\end{tabular}

Factor coding is Coded

Sum of squares is Type III - Partial

The Model F-value of $\mathbf{2 . 6 9}$ implies the model is significant There is only a $0.67 \%$ chance that an $F$-value this large could occur due to noise.

P.values less than 0.0500 indicate model terms are significant. in this case A is a significant model term. Values greater than 0.1000 indicate the model terms are not significant. If there are many insignificant model terms (not counting those required to support hierarchy), modet reduction may improve your model.

\section{Fit Statistics}

\begin{tabular}{|l|r|l|l|l|}
\hline & & & \\
\hline Std. Dev. & 0.3040 & $R^{\mathbf{2}}$ & 0.7653 \\
\hline Mean & 68.34 & Adjusted $\mathbf{R}^{\mathbf{2}}$ & 0.6772 \\
\hline C.V. \% & 0.4448 & Predicted $\mathbf{R}^{\mathbf{2}}$ & 0.4719 \\
\hline & & Adeq Precision & 5.3559 \\
\hline
\end{tabular}

The Predicted $R^{2}$ of 0.4719 is not as close to the Adjusted $R^{2}$ of 0.6772 as one might normally expect; i.e. the difference is more than 0.2. This may indicate a large block effect or a possible problem with your model and/or data. Things to consider are model reduction, response transformation, outliers, etc. All empirical models should be tested by doing confirmation runs.

Adeq Precision measures the signal to noise ratio. A ratio greater than 4 is desirable. Your ratio of 5.356 indicates an adequate signal. This model can be used to navigate the design space. 


\section{CONCLUSION}

Solid dispersion of furosemide was prepared by the solvent evaporation technique using hydrogel isolated from the seeds of Lepidium sativum (gel) as a novel carrier. Dissolution efficiency of solid dispersion of furosemide (Furosemide: Dried gel in 1:3 proportions) was improved from $13.54 \%$ (plain furosemide) to $69.12 \%$ in the first $60 \mathrm{~min}$. Molecular dispersion of furosemide in carrier (in its solid dispersion form) was found to be the major cause of its improved dissolution. Solid dispersion of furosemide was found to be stable and recrystallization was mitigated during stability studies. This was due to the selection of proper hydrophilic carrier and its inclusion in the solid dispersion in appropriate proportion. The stability of amorphous solid dispersion was found to be due to intermolecular interaction between furosemide and novel carrier through hydrogen bonding and confirmed by FTIR studies. Immediate-release capsule formulation of amorphous solid dispersion of furosemide was optimized by adopting factorial design. Data of dissolution efficiency of factorial batches was analyzed by ANOVA by using Design Expert (Demo Version 11) and results revealed that the levels of factors selected would be useful to navigate design space.

\section{ACKNOWLEDGMENT}

The authors thank Cipla Ltd., Kurkhumbh, Pune, for providing furosemide as a gift sample for this work. They also thank Dr. K. S. Bhise, Principal of MCES's Allana College of Pharmacy, Pune for providing facilities to carry out research work.

\section{FUNDING}

Nil

\section{AUTHORS CONTRIBUTIONS}

The research idea was set with guidance of Prof. Dr. Sharwaree R. Hardikar. The research work was done by Shakil S. Mulla. The manuscript was prepared by Shakil S. Mulla and the critical revision of the manuscript was done by Prof. Dr. Sharwaree R. Hardikar. Calculations and data interpretation was supported by Prof. Dr. Sharwaree R. Hardikar.

\section{CONFLICTS OF INTERESTS}

Declared none

\section{REFERENCES}

1. Charalabidis A, Sfouni M, Christel Bergström C, Macheras P. The Biopharmaceutics Classification System (BCS) and the Biopharmaceutics Drug Disposition Classification System (BDDCS): beyond guidelines. Int J Pharm 2019;566;264-81.

2. Butler JM, Dressman JB. The developability classification system: Application of biopharmaceutics concepts to formulation development. J Pharm Sci 2010;99:4940-54.

3. Gurunath S, Pradeep Kumar S, Basavaraj NK, Patil PA. Amorphous solid dispersion method for improving oral bioavailability of poorly water-soluble drugs. J Pharm Res 2013;4:476-80.

4. Razmkhah S, Razavi SMA, Mohammadifar MA, Koocheki A, Ale MT. Stepwise extraction of Lepidium sativum seed gum: Physicochemical characterization and functional properties. Int J Biol Macromol 2016;88:543-64.

5. Srinarong P, Faber JH, Visser MR, Hinrichs WLJ, Frijlink HW. Strongly enhanced dissolution rate of fenofibrate solid dispersion tablets by incorporation of superdisintegrants. Eur J Pharm Biopharm 2009;73:154-61.

6. Vikas A Saharan, Vipin Kakkar, Mahesh Kataria, Manoj Gera, Pratim K Choudhury. Dissolution enhancement of drugs-part i: technologies and effect of carriers. J Health Res 2009;2:107-24.

7. Patel HH, Kardile D, Puvar AN, Prajapati RK, Patel MR. Lepidium sativum: natural superdisintegrant for fast dissolving technology. Int J Pharm Appl Sci 2011;2:56-62.
8. Jermain SV, Brough C, Williams RO. Amorphous solid dispersions and nanocrystal technologies for poorly watersoluble drug delivery-an update. Int J Pharm 2018;535:379-92.

9. Hebbink G, Dikhoff HJ. Chapter 5-application of lactose in the pharmaceutical industry evolutionary role. Health Effects and Applications; 2019. p. 175-229.

10. Petrovick PR, Jacob M, Gaudy D, Bassani VL, Guterres SS. Influence of adjuvants on the in vitro dissolution of hydrochlorothiazide from hard gelatin capsules. Int J Pharm 1991;76:49-53.

11. Kokilambigai KS, Laxmi KS. A QbD assisted spectrophotometric methods for the quantification of cefixime trihydrate using two oxidative coupling agents. Asian J Pharm Clin Res 2019;12:234-42.

12. Vasconcelos T, Marques S, Das Neves J, Sarmento B. Amorphous solid dispersions: Rational selection of a manufacturing process. Adv Drug Delivery Rev 2016;12:85101.

13. U. S. P. National Formulary. Vol. 2; 2014. p. 3102-3.

14. Parfati N, Rani KC, Charles N, Geovanny V. Preparation and evaluation of Atenolol $\beta$-cyclodextrin orally disintegrating tablets using coprocessed crospovidone-sodium starch glycolate. Int J Appl Pharm 2018;10:190-4.

15. ICH Q8 (R2), Stability testing of new drug substances and products; 2003. Available from: http://www.ich.org [Last accessed on 10 Oct 2019].

16. De Muth JE. Factorial design: an introduction. In: Basic statistics and pharmaceutical statistical applications. New York: CRC Press; 2014. p. 269-308.

17. Bolton S, Bon C. Factorial designs. In: Pharmaceutical Statistics: Practical and Clinical Applications. New York: Marcel Dekker; 2009. p. 222-39.

18. Razmkhah S, Razavi SMA, Mohammadifar MA, Arash K, Ale MT. Stepwise extraction of Lepidium sativum seed gum: Physicochemical characterization and functional properties. Int J Bio Macromol 2016;88:553-64.

19. Behrouzian F, Razavi SMA, Phillips GO. Cress seed (Lepidium sativum) mucilage, an overview. Bio Ca Die Fib 2014;3:17-8.

20. Abdulrahman M, Fahad J, Khalid A. Furosemide. In: Florey K, Al-Badr AA, Forcier GA, Brittain HG, Grady LT. editors. Analytical profiles of drug substances. New Jersey: Academic Press, Inc; 1990. p. 153-84.

21. Dwi S, Retno S, Helmy Y, Riesta P. Preparation and characterization of Artesunate Nicotinamide cocrystal by Solvent evaporation and slurry method. Asian J Pharm Clin Res 2014;07:62-5.

22. Gupta SP. Tests of significance for small samples. In: Statistical methods. New Delhi: Sultan Chand and Sons; 1994. A.3.31A.3.71.

23. Chan SY, Chung YY, Cheah XZ, Tan EYL, Quah J. The characterization and dissolution performances of spray-dried solid dispersion of ketoprofen in hydrophilic carriers. Asian J Pharm Sci 2015;10:372-85.

24. Jermain SV, Brough C, Williams RO. Amorphous solid dispersions and nanocrystal technologies for poorly watersoluble drug delivery-an update. Int J Pharm 2018;535:379-92.

25. Shirke SH, Shewale SB, Kulkarni AS, Aloorkar NH. Solid dispersion: a novel approach for poorly water soluble drugs. Int J Curr Pharm Res 2015;7:1-8.

26. Zhang D, Lee YC, Shabani Z, Lamm CF, Zhu W, Li Y, et al. Processing impact on the performance of solid dispersions. Int J Pharm 2018;142:1-13.

27. Hebbink G, Dikhoff HJ. Chapter 5-application of lactose in the pharmaceutical industry evolutionary role. In: Health Effects, and Applications; 2019. p. 175-229.

28. Kubbinga M, Moghani L, Langguth P. Novel insights into excipient effects on the biopharmaceutics of APIs from different BCS classes: lactose in solid oral dosage forms. Eur J Pharm Sci 2014;61:27-31. 